\title{
Précis of Writing the Book of the World
}

THeOdore Sider $\quad$ July I 8 , 2013

Nelson Goodman (I978) said that there is no "ready-made world". Human physicists use words like 'charge', 'mass', and 'distance', but nothing would be wrong with instead describing the world using cooked-up words derived from those of physics in the way that Goodman's 'grue' and 'bleen' are derived from 'green' and 'blue'.

My central thesis is that there $i s$ a ready-made world. There is a set of objectively privileged concepts: the "fundamental", or "joint-carving", or "structural" ones. A complete description of the world using these concepts-the "book of the world"- - gives reality's fundamental structure. A description of the world using cooked-up concepts can be true, and even in a sense equivalent to the book of the world, but is nevertheless representationally deficient since its structure does not match the world's structure.

Many of the traditional questions of metaphysics are about the nature of reality's fundamental structure. Is reality "ultimately" just physical, or is there also a mental aspect? This is a question of whether the book of the world mentions mentality — of whether mental concepts are structural.

Realism about structure is in same camp as realism about natural kinds, particularly as developed by David Lewis (1983, I986, pp. 59-69) in his theory of natural properties and relations. But structure differs from naturalness in important ways, especially in being applicable to words of arbitrary grammatical category, not just to predicates. We may assert or deny that a modal operator, quantifier, or even a sentential connective like 'and' or 'not' is structural. This is important because the traditional metaphysical questions about what reality is ultimately like are not limited to questions about predicate-structure. Is reality ultimately amodal, or is the distinction between necessity and possibility written into the book of the world? This is the question of whether certain sentential operators - the modal operators $\square$ and $\diamond$ - carve at the joints, not a question about predicates. Does reality have a distinguished entity-structure, or are there-as Goodman thought-multiple equally good ways of carving reality into domains of objects? This is the question of whether quantifiers carve at the joints, not a question about predicates.

Questions about joint-carving are central to certain questions about objectivity. Some questions about objectivity are simply questions about whether various facts are mind-dependent (in various senses). But even when we use 
language to express mind-independent facts, there may yet be a failure of objectivity in a further, and largely neglected, sense. For suppose that we (or our biology or circumstances) have chosen one of many candidate meanings for a word, where the unchosen candidates carve at the joints equally well and would have played a similar semantic role to our actual choice. Then even though we express mind-independent facts with the word, the facts we express are in a sense a projection of the choice of which candidate to mean. Even if 'Europe' is a proper name for a certain physical region of the planet, with no political dimension to its meaning (undoubtedly an oversimplification), the choice of the particular region signified is a projection of historical and political facts. Thus there can be a certain failure of objectivity in our talk about Europe's borders, say, even if the facts we express are mind-independent. This is not the case with words from physics, for there are no equally joint-carving candidates for physical words that would have played similar semantic roles to our actual semantic choices.

This further way in which objectivity can fail is, I believe, essentially involved in the deepest critiques of contemporary metaphysics. For instance, Eli Hirsch (20I I) has been arguing for years (in the spirit of Rudolf Carnap (I950) and Hilary Putnam (1987)) that debates over the ontology of composite and persisting objects (Chisholm versus Lewis versus van Inwagen...) are "merely verbal" in the sense that each position offered up in the debate comes out true under some possible meaning for the crucial expressions in the debate. Peter van Inwagen (1990) and Lewis ( 1986 , pp. 2 I I-3) think that they substantively disagree over whether there exist tables and chairs exist (in addition to "particles arranged table-wise"). But according to Hirsch's thesis of "quantifier variance", quantifiers such as 'there exist' can be given multiple meanings. Under some, van Inwagen's claims come out true; under others, Lewis's claims come out true; and the only real issue is one of conceptual analysis: which meaning is the ordinary English one? Hirsch stresses that his quantifier variance is compatible with "realism", but by that he means merely that the facts we express under any particular quantifier meaning are mind-independent. At a deeper level his position is anti-realist, since he denies that the quantificational facts are objective in the further, neglected sense. Quantificational facts on his view are a projection of our conceptual scheme, which is just one amongst many equally good possible ones.

My own view is that the best hope for a sustainable defense of ontology requires embracing realism about quantificational structure. For if in addition to Hirsch's multiple meanings for 'there is', there is also a joint-carving sense 
of 'there is', then there remains a substantive question about ontology: that of what exists in this joint-carving sense.

It can be argued that there is indeed a joint-carving sense of 'there is', and thus that ontology is substantive. But whether this is so is itself a substantive question, over which there is room for debate. In other cases, such as certain debates about causation, I myself would stand with the Carnapian side. There is arguably no joint-carving notion of causation- "reality is fundamentally acausal"; this can then be used to argue that certain debates over the nature of causation are merely verbal in something like Hirsch's sense. But setting aside questions about particular cases, the larger issue is that many questions about meta-metaphysics are about objectivity in the further sense, and ultimately turn on where reality's joints lie.

I understand the fundamental facts as those involving structural concepts, and I do not define 'structure' in modal terms. (In fact, I do not define it at all; structure is primitive-indeed, structural!) Thus I join many recent authors (such as Karen Bennett (2OI3), Kit Fine (200I, 20I2), and Jonathan Schaffer (2009)) in refusing to understand notions in the vicinity of fundamentality in modal terms. But there are differences between me and these other authors. For instance, Fine's notion of ground is a propositional and comparative notion: entire propositions ground and are grounded, and ground is a relation between pairs of propositions. Structure on the other hand is subpropositional and absolute: it is parts of propositions (or parts of sentences, to put it linguistically) that are structural, and a single proposition-part, rather than a pair, is structural. These and other subtle differences turn out to matter in surprising ways.

\section{References}

Bennett, Karen (2013). Making Things Up. Oxford: Oxford University Press. Forthcoming.

Carnap, Rudolf (1950). "Empiricism, Semantics and Ontology." Revue International de Philosophie 4: 20-40. Reprinted in Meaning and Necessity: A Study in Semantics and Modal Logic, 2nd edn. University of Chicago Press, Chicago.

Fine, Kit (200I). "The Question of Realism.” Philosopher's Imprint I: I-30.

- (2012). "Guide to Ground." In Fabrice Correia and Benjamin Schnieder (eds.), Metaphysical Grounding: Understanding the Structure of Reality. Cambridge: Cambridge University Press. 
Goodman, Nelson (1978). Ways of Worldmaking. Indianapolis: Hackett.

Hirsch, Eli (20 I I). Quantifier Variance and Realism: Essays in Metaontology. New York: Oxford University Press.

Lewis, David (1983). "New Work for a Theory of Universals." Australasian Fournal of Philosophy 61: 343-77. Reprinted in Lewis 1999: 8-55.

- (I986). On the Plurality of Worlds. Oxford: Blackwell.

- (1999). Papers in Metaphysics and Epistemology. Cambridge: Cambridge University Press.

Putnam, Hilary (1987). "Truth and Convention: On Davidson's Refutation of Conceptual Relativism." Dialectica 4I: 4I-67.

Schaffer, Jonathan (2009). "On What Grounds What." In David J. Chalmers, David Manley and Ryan Wasserman (eds.), Metametaphysics, 347-83. Oxford: Oxford University Press.

van Inwagen, Peter (I990). Material Beings. Ithaca, NY: Cornell University Press. 